\title{
Overweight/obesity among adults in North- Western Ethiopia: a community-based cross sectional study
}

\author{
Teferi Mekonnen ${ }^{1 *}$, Worku Animaw ${ }^{2}$ and Yeshaneh Seyum²
}

\begin{abstract}
Background: Nowadays adulthood overweight/obesity is an emerging public health problem in developing countries. There is no information on magnitude and contributing factors of adulthood overweight/obesity in Ethiopia, particularly in North West region of the country. Thus, the aim of this study was to assess magnitude and contributing factors of adulthood overweight/obesity in North West region of Ethiopia.

Methods: A community-based cross-sectional study was conducted from September1, 2015 to November 30, 2015 in northwest region of Ethiopia particularly Bahir-Dar city and its rural districts. A total of 1484 adult participants were recruited in the study. Stratified multistage followed by systematic random sampling technique was employed to select participants. Overweight/obesity was determined using center for diseases control cutoff points. A multivariable binary logistic regression model was fitted to identify factors associated with overweight/obesity. Adjusted Odds Ratio (AOR) with the corresponding 95\% Confidence Interval (Cl) was calculated to show the strength of association.

Results: A total of 1405 adults were participated in the study with a response rate of $94.7 \%$. This study indicated that 11.3 (95\% Cl: $9.6,13.1)$ adults were overweight and obese of which about $9.3 \%$ and $2 \%$ of adults were overweight and obese, respectively. The higher odds of being Overweight/Obese were noted among urban residents, females and older age. However performing mild to moderate physical activity [AOR $=0.608,95 \% \mathrm{Cl}: 0.37$, $0.99]$ and consumption of fruit and vegetable $[A O R=0.51,95 \% \mathrm{Cl}: 0.34,0.77]$ were found to be protective against overweight/obesity.

Conclusion: Though, it was a problem of developed countries adulthood overweight /obesity is emerged as a public health problem among adults in Ethiopia particularly in the study area, northwest region. Hence, preventive interventions focusing on urban residents, females through encouraging Physical activity, fruit and vegetable consumption is essential to prevent emergence of adulthood overweight/obesity.
\end{abstract}

Keywords: Overweight/obesity, Adults, Ethiopia

\section{Background}

Overweight/Obesity is defined as the abnormal or excessive accumulation of body fat resulting from positive energy imbalance expressed by a body mass index (BMI) of $25-29.9$ and $\geq 30 \mathrm{~kg} / \mathrm{m}^{2}$, respectively $[1,2]$.

Overweight/Obesity have been increasing at an alarming rate in both the developed and developing countries

\footnotetext{
* Correspondence: tmekonnen16@yahoo.com

'Bahir Dar University, School of Public Health, Public Health Nutrition Unit,

Bahir Dar, Ethiopia

Full list of author information is available at the end of the article
}

during the last few decades, though it was historically a problem of the developed countries [3, 4].

In developing countries, along with economic development which leads to nutrition transition, numbers of people with overweight/obesity are increasing attributed by adopting a modern lifestyle with less physical activity and excessive consumption of energy-dense foods [5, 6].

Over the past 30 years, Overweight/obesity has been steadily increasing even in low-income countries, including those in Sub-Saharan Africa (SSA) [7, 8]. In SubSaharan African countries, overweight/obesity levels are 
still lower than in high-income countries but certainly higher than they were two decades ago and increasing at alarming rates $[8,9]$.

Demographic Health Survey (DHS) analysis of 32 SubSaharan African countries revealed that the pooled prevalence of overweight in the region was $15.9 \%$ with the lowest in Madagascar 5.6\% and the highest in Swaziland $27.7 \%$, Similarly, the prevalence of obesity was also lowest in Madagascar 1.1\% and highest in Swaziland 23.0\% [10]. Pocket studies in Tanzania revealed that the prevalence of overweight and obesity among adults were $24.1 \%$ and $19.2 \%$, respectively [11]. Another study conducted in Malawi revealed that the prevalence of overweight and obesity were $20.7 \%, 7.4 \%$ respectively while overweight/obesity was $28.1 \%$ with the highest prevalence in urban areas that rural area [12].

Analysis of Ethiopian Demographic Health Survey (EDHS) found that the prevalence of overweight and obesity for urban settings were $12.1 \%$ and $2.8 \%$, respectively [13]. Another study in Addis Ababa found that $25.7 \%$ of women were overweight and $10.2 \%$ were obese. A study among permanent employees of the Commercial Bank of Ethiopia and teachers in government schools of Addis Ababa found that 24.7\% of men and $25.7 \%$ of women were overweight and $2.1 \%$ men and 10.2 women were obese $[9,14,15]$. A study in Gondar revealed that the prevalence of overweight was $32.4 \%$ while the prevalence of obesity was $16.2 \%$ [16].

Different factors contribute to overweight and obesity among adults. Among the contributing factors identified, age $[11,17]$, sex $[2,11,15,18]$, educational status [11, $18-21]$, marital status $[4,11,19,20,22,23]$, occupational status $[2,23,24]$, income $[6,11,20,25]$, residences $[14,17,18,26,27]$, diet $[19,28]$, physical activity $[2,11,23]$, alcohol consumption $[4,11,23]$, and smoking $[7,9,29,30]$ were frequently reported in various studies.

In Ethiopia, particularly in the study area, there was no information regarding the prevalence and contributing factors of overweight/obesity among adults. Thus, this study determined the prevalence of overweight/obesity and associated factors among adults in the northwest region of Ethiopia. The information can be used as a baseline evidence for program planner, policymakers, researchers and organizations who are working on prevention of chronic non-communicable diseases.

\section{Methods}

\section{Study design and period}

A community-based quantitative cross-sectional study design was employed from 1st of September to 30th of November 2015 in north-western Ethiopia particularly Bahir-Dar city and its rural districts.

\section{Sample size and sampling procedure}

The sample size was determined by using Epi $\operatorname{Info}^{\text {Tw }} 7$ by considering the following assumptions, $28 \%$ prevalence of overweight EDHS 2011 result [13], design effect of $1.5,15 \%$ non-response rate, $3 \%$ confidence limit and the final sample size was 1484 . A systematic random sampling technique was used to select a total of 1484 adult participants.

\section{Study population}

All adults who were living in the northwestern region of Ethiopia were targeted for the study. All adults aged $\geq 18$ years who were living in selected districts during the data collection period were included in the study. Seriously ill adults during data collection were excluded from the study.

\section{Data collection tools and procedures}

A structured pretested questionnaire was adapted from the WHO STEPwise questionnaire for Chronic Disease Risk Factor Surveillance was used in this study [31]. Data about dietary habit and physical activity were collected for a week duration based on the WHO STEPwise approach to chronic disease risk factor surveillance (STEPS) questionnaire.

The English version of the questionnaire was translated to the local language, Amharic, and back to English by a professional translator. Twenty four clinical diploma nurse data collectors and two BSc nurse supervisors were trained for data collection and supervision for two days. Finally, data were collected through interviewer-administered technique.

\section{Anthropometric measurements}

The anthropometric assessment was done according to the standardized procedures stipulated by the Food and Nutrition Technical Assistance (FANTA) Anthropometric Indicators Measurement Guide [32]. Height was measured to the nearest $0.1 \mathrm{~cm}$ in standing position at Frankfurt plane with the occipital, shoulder and the buttock touches the vertical stand using a Stadiometer Seca (Germany). Weight was measured to the nearest $0.1 \mathrm{~kg}$ using an electronic weighing scale with wearing light clothes and with no shoes using Seca digital weighing scale. Finally, body mass index was computed.

\section{Data quality control}

Training was given for data collectors and supervisors. The questionnaire was developed in English and then translated to Amharic and back to English then review was made for consistency of the translation. The data were collected after pre-testing the instrument. Regular supervision was made by supervisors. The collected data were reviewed and checked for completeness and 
accuracy by supervisors and investigator, and weight scale was calibrated and placed in levelled flat surface before each measurement was taken. Continuous checkups of the scale were carried out.

\section{Data processing and analysis}

The data were coded on pre-arranged coding sheet by the principal investigator then entered into Epidata 3.1 and cleaned, processed and analyzed using SPSS version 20. The information obtained was described by using mean, frequencies, proportions, and tables. Body mass index was computed and Center for Diseases Control standard was used as a reference for classifying overweight/obesity.

Both bi-variable and multivariable logistic regression was used. Variables in the bi-variable logistic regression analysis having $P$-value of less than 0.2 were included in the multivariable logistic regression analysis to identify predictors that showed significant associations with overweight/obesity. After checking for multicollinearity enter method was used and Hosmer and Lemeshow goodness of model fit test was 0.88 . Finally, the odds ratios with $95 \%$ confidence intervals were reported to indicate the strength of associations.

\section{Results}

Socio-demographic and economic characteristics

In this study, a total 1484 adult participants were recruited and 1405 of them participated in the study with a response rate of $94.7 \%$. Of the total respondents, $56.7 \%$ were females, $65.8 \%$ were married and $65.1 \%$ were selfemployed. With regard to educational status $37.4 \%$ were unable to read and write and of the total population included in the study, $50.8 \%$ were rural residents. The mean age of the participants were 37 years with standard deviation of 16 . Majority of the respondents (91.6\%) were Orthodox Christians. The households' monthly mean income was $2251.55 \pm 1245.757$ Ethiopian Birr (Table 1).

\section{Dietary habit and physical activity among adults residing} in Northwest Ethiopia

About 843(60.2\%) had consumed soft drinks always, $520(37.1 \%)$ had never consumed soft drinks and $37(2.6 \%)$ had sometimes consumed soft drinks. About 788(56.3\%), 379(27.1\%) and (233(16.6\%) had consumed coffee always sometimes, and never respectively. About 350 (25\%), 817(58.4\%) and 233(16.6\%) had always, sometimes and never used sugar added to food or drink respectively. About 73(5.2\%) had ever chewed chat. About $60.9 \%$ had consumed fruit and vegetables and 745(53.2\%) had performed mild to moderate physical activity (Table 2).
Table 1 .Socio-demographic characteristics of adults in Northwestern Ethiopia, 2015 ( $n=1405)$

\begin{tabular}{|c|c|c|c|}
\hline Variable & & Frequency & Percentage (\%) \\
\hline \multirow[t]{2}{*}{ Sex } & Male & 609 & 43.3 \\
\hline & Female & 796 & 56.7 \\
\hline \multirow[t]{5}{*}{ Age } & $<23$ years & 294 & 21.0 \\
\hline & 24-28 years & 270 & 19.3 \\
\hline & 29-39 years & 254 & 18.1 \\
\hline & $37-50$ years & 312 & 22.3 \\
\hline & $>50$ years & 270 & 19.3 \\
\hline \multirow[t]{3}{*}{ Religion } & Orthodox & 1283 & 91.6 \\
\hline & Muslim & 97 & 6.9 \\
\hline & Protestant and others & 20 & 1.4 \\
\hline \multirow[t]{2}{*}{ Residence } & Urban & 691 & 49.2 \\
\hline & Rural & 714 & 50.8 \\
\hline \multirow[t]{4}{*}{ Occupational status } & Student & 110 & 7.9 \\
\hline & Formally Employed & 161 & 11.5 \\
\hline & Self Employed & 912 & 65.1 \\
\hline & Daily Laborer & 217 & 15.5 \\
\hline \multirow[t]{4}{*}{ Marital status } & Single & 319 & 22.8 \\
\hline & Married & 922 & 65.9 \\
\hline & Divorced & 72 & 5.1 \\
\hline & Widowed & 87 & 6.2 \\
\hline \multirow[t]{2}{*}{ Income } & $<2250$ Et.Birr & 664 & 41.4 \\
\hline & $>2250$ Et Birr & 820 & 58.6 \\
\hline
\end{tabular}

Table 2 Dietary habit and physical activity of adults residing in Northwest region of Ethiopia, $2015(n=1405)$

\begin{tabular}{llll}
\hline Variable & & Frequency & Percentage (\%) \\
\hline Soft drink intake & Always & 37 & 2.6 \\
& Sometimes & 843 & 60.2 \\
& Never & 520 & 37.1 \\
Coffee drinking & Always & 788 & 56.3 \\
& Sometimes & 379 & 27.1 \\
& Never & 233 & 16.6 \\
Sugar added to any food & Always & 350 & 25.0 \\
/drinks & Sometimes & 817 & 58.4 \\
& Never & 233 & 16.6 \\
Ever chew chat & Yes & 73 & 5.2 \\
& No & 1327 & 94.8 \\
Fruit and vegetable intake & Yes & 852 & 60.9 \\
& No & 655 & 46.8 \\
Performing mild to moderate & Yes & 745 & 53.2 \\
Physical activity & No & 655 & 46.8 \\
\hline
\end{tabular}




\section{Anthropometric measurements and prevalence of overweight /obesity among adults in North West region of Ethiopia, 2015}

The mean height \pm SD was $162 \pm 0.09 \mathrm{~cm}$ and the mean weight \pm SD was $55 \pm 9 \mathrm{~kg}$.

The overall prevalence of overweight/obesity was 11.3 (95\% CI: 9.6, 13.1), in which $9.3 \%$ and $2 \%$ of adults were overweight and obese respectively. The proportions of overweight/obesity among female and male were 15\% and $6.4 \%$ respectively. Moreover $18.7 \%$ urban residents and $4.2 \%$ rural residents were overweight/ obese.

\section{Factors associated with overweight/obesity among adults in North West region of Ethiopia}

The multivariable logistic regression analysis revealed that being female, being in an urban resident, performing mild to moderate physical activity; fruit and vegetable intake and age were significantly associated with adulthood overweight and obesity. Accordingly, the odds of being overweight /obese were 3.12 times higher in urban residents as compared to rural residents [AOR = 3.12, 95\% CI: 1.76, 5.54]. Similarly, the higher odds of being overweight/obesity were noted among females as compared to males $[\mathrm{AOR}=, 2.72$, CI $(1.74,4.23]$ and a higher odds of being overweight/obese were noted in the age category of $24-28$ years $[A O R=2.82,95 \% \mathrm{CI}$ : $1.33,5.98], \quad 29-36$ years $[\mathrm{AOR}=5.3, \quad 95 \%$ CI: 2.43, 11.56],37-50 years $[\mathrm{AOR}=6.06,95 \% \mathrm{CI}: 2.77,13.29]$, greater than 50 years $[\mathrm{AOR}=7.14,95 \% \mathrm{CI}: 3.23,15.79$ ] as compared with age category of 18-23 years old.

A lower odds of being overweight/obese were noted among those who performed mild to moderate physical activity and who had consumed fruits and vegetables. Those who had performed mild to moderate physical activity were $39.2 \%$ times less likely to develop overweight/obesity $[\mathrm{AOR}=0.608,95 \% \mathrm{CI}: 0.37,0.99$ ] and those who had consumed fruits and vegetables were $49 \%$ times less likely to develop overweight obesity [AOR = 0.51, 95\% CI: 0.34, 0.77] (Table 3) than their counterparts.

\section{Discussions}

This study demonstrated that the overall prevalence of overweight/obesity among adults in northwestern region of Ethiopia was found to be $11.3 \%$ [95\% CI: 9.6-13.1], of which $9.3 \%$ were overweight and $2.0 \%$ were obese. The finding of this study is consistent with the evidence from EDHS data analyzed for the urban setting where $12.1 \%$ and $2.8 \%$ were overweight and obese respectively [13].

The finding of the study is also lower than the pooled prevalence of Demographic Health Survey data of 32 sub-Saharan African countries yielding 15.9\% prevalence of overweight in the region [10] and studies done in Malawi (28.1\%) and Tanzania in which the prevalence of overweight and obesity among adults were $24.1 \%$ and $19.2 \%$ [33]. The discrepancy might be due to the disparities in socio-demographic characteristics and dietary habits.

In this study female adults were more likely to be overweight/ obese as compared to males. The finding is consistent with the study done in Ethiopia and Ghana[13, 34]. This might be due to fact that females can carry more amount of fat as compared to males.

Residency was found to be one of the factors associated with the nutritional statuses of the participants. A higher odds of being overweight/obese were found in urban residents as compared to the rural residents. This finding is consistent with the study done in Addis

Table 3 Factors associated with overweight/obesity among adults in Northwestern region of Ethiopia, $2015(n=1405)$

\begin{tabular}{|c|c|c|c|c|c|}
\hline \multirow[t]{2}{*}{ Variables } & & \multicolumn{2}{|c|}{ Overweight/obesity } & \multirow[t]{2}{*}{$\operatorname{COR}(95 \% \mathrm{Cl})$} & \multirow[t]{2}{*}{ AOR $(95 \% \mathrm{Cl})$} \\
\hline & & Yes & $\mathrm{No}$ & & \\
\hline \multirow[t]{2}{*}{$\overline{\text { Sex }}$} & Male & 39 & 570 & 1 & \\
\hline & Female & 120 & 676 & $2.59(1.78-3.79)$ & $2.72(1.74-4.23) * *$ \\
\hline \multirow[t]{2}{*}{ Performing mild to moderate physical activity } & Yes & 43 & 705 & $0.28(0.19-0.41)$ & $0.61(0.37-0.99) * *$ \\
\hline & No & 116 & 541 & 1 & \\
\hline \multirow[t]{2}{*}{ Residence } & Rural & 30 & 684 & 1 & \\
\hline & Urban & 129 & 562 & $5.23(3.46-7.91)$ & $3.12(1.76-5.54) * *$ \\
\hline \multirow[t]{5}{*}{ Age category } & $<23$ & 14 & 183 & 1 & \\
\hline & $24-28$ & 25 & 246 & $2.05(1.05-4.04)$ & $2.82\left(1.33-5.98^{* *}\right.$ \\
\hline & $29-36$ & 34 & 220 & $3.12(1.64-5.97)$ & $5.30(2.43-11.56) * *$ \\
\hline & $37-50$ & 38 & 274 & $2.80(1.49-5.29)$ & $6.06(2.77-13.29) * *$ \\
\hline & $>50$ & 48 & 223 & $4.35(2.34-8.09)$ & $7.14(3.23-15.79) * *$ \\
\hline \multirow[t]{2}{*}{ Fruit and vegetable intake } & Yes & 40 & 509 & $0.49(0.33-0.71$ & $0.51(0.34-0.77) * *$ \\
\hline & No & 119 & 737 & 1 & \\
\hline
\end{tabular}


Ababa, Gondar, Benin and Chennai [14, 17, 18, 26, 28]. This might be due to the fact, in urban resident's practice more sedentary lifestyle and faster nutrition transitions like focusing on synthetic and energy-dense foods.

A higher odds of being overweight/obese was noted in the age category of 24 years and above. This finding is consistent with the study done in Ghana and EDHS2011 finding $[4,13,35,36]$. This might be due to the fact that as age increases the likelihood of sedentary life style would also increased [37, 38]. However, performing mild to moderate physical activity were found to be protective against overweight/obesity in which those who had performed mild to moderate physical activity were less likely to develop overweight/obesity as compared to those who did not. The finding of this study is consistent with the study done in Tanzania [33]. This might be due to the fact that physical activity determines the amount of calories either spent or stored in the body in the form of fat and maintains healthy weight status and because of its potential major impact on body composition, metabolism, and increasing energy expenditure.

Fruit and vegetable consumptions were found to be protective against overweight/obesity in which those who consumed fruit and vegetables were less likely to develop overweight/obesity. The finding of this study is consistent with the study done in Chennai [19]. This might be due to the fact that their bulk and low energy density of fruit and vegetable (with a high amount of water and fiber) are believed to reduce energy dense food consumption and helps to easily attain satiety.

\section{Limitation of study}

Since it is cross-sectional study it is not far from the pitfalls of cross-sectional study. History of past diseases or present history of co-morbidity was not assessed. Frequency and portion size of fruit and vegetable consumptions, alcohol consumptions were not included in the final model due to issues of recall bias.

\section{Conclusion}

In this study, the overall prevalence of overweight/obesity among adults in northwest region of Ethiopia was found to be $11.3 \%$. The higher odds of being overweight /obese were noted among females, urban residents and older age participants. Whereas performing mild to moderate physical activity and consumption of fruits and vegetables were found to be protective against overweight/obesity. As this evidence shows overweight/obesity which was a problem of the developed country has now emerged in Ethiopia particularly in the study area, northwest region. Hence, preventive interventions by focusing on urban residents, females through encouraging physical activity and fruit and vegetable consumption is essential to prevent the emergence of adulthood overweight/obesity and hence could prevent its related health problems such as diabetes mellitus, hypertension, heart problems, stroke and many more.

\section{Abbreviations}

AOR: Adjusted odds ratio; BMI: Body mass index; Cl: Confidence interval; EDHS: Ethiopian Demographic Health Survey; WHO: World Health Organization

\section{Acknowledgments}

The authors would like to thank all respondents for their willingness to participate in the study, the data collectors and supervisors. They are also grateful to Amhara region Administration and district and sub-city office and Bahir Dar University for their financial and material support.

\section{Funding}

This study was funded by Bahir Dar University. The views presented in this manuscript are of the authors and not necessarily express the views of the funding organizations. The funding organizations were not involved in the design, data collection, analysis, and interpretation of the study.

Availability of data and materials

Data will be available upon request from the corresponding author.

\section{Author contributions}

TM, WA and YS conceived the study, developed the tool, coordinated the data collection activity, carried out the statistical analysis and drafted the manuscript and reviewing the manuscript. All authors read and approved the final manuscript.

\section{Ethics approval and consent to participate}

Ethical approval and clearance was obtained from Institutional Review Board of Bahir Dar University. After clearly explaining the objective of the study, written consent was taken from each participant before conducting the interview and measurements. Data were kept confidential.

\section{Competing of interest}

The authors declare that they have no competing interests.

\section{Consent for publication}

Not applicable.

\section{Publisher's Note}

Springer Nature remains neutral with regard to jurisdictional claims in published maps and institutional affiliations.

\section{Author details}

'Bahir Dar University, School of Public Health, Public Health Nutrition Unit, Bahir Dar, Ethiopia. ${ }^{2}$ Bahir Dar University, Department of Nursing, Bahir Dar, Ethiopia.

Received: 22 September 2017 Accepted: 8 February 2018

Published online: 05 March 2018

\section{References}

1. Center For Diseases Control and Prevention(CDC): Defining Adult Overweight and Obesity. In.; 2017.

2. Kasu ES, Ayim A, Tampouri J. Prevalence of obesity among health workers in Kadjebi District of Ghana. Journal of Biology, Agriculture and Healthcare. 2015;5(2):155-66.

3. PDLLA AJO. Prevalence of overweight and obesity in an institutionalized multi ethnic based male adult sample. International Journal of Humanities and Social Science. 2013;3(5):234-7.

4. Sen J, Mondal N, Dutta S. Factors affecting overweight and obesity among urban adults: a cross-sectional study. Epidemiology Biostatistics and Public Health. 2013;10(1):e8741-11.

5. Amin F, Fatima SS, Islam N, Gilani AH. Prevalence of obesity and overweight, its clinical markers and associated factors in a high risk southAsian population. BMC obesity. 2015;2(1):16. 
6. Żukiewicz-Sobczak W, Wróblewska P, Zwoliński J, Chmielewska-Badora J, Adamczuk P, Krasowska E, Zagórski J, Oniszczuk A, Piątek J, Silny W. Obesity and poverty paradox in developed countries. Ann Agric Environ Med. 2014; 21(3):590-4.

7. Annibale Cois CD. Obesity trends and risk factors in the south African adult population. BMC Obesity. 2015:2(42):1-10.

8. Steyn NP, Mchiza ZJ. Obesity and the nutrition transition in sub-Saharan Africa. Ann N Y Acad Sci. 2014;1311:88-101.

9. Tebekaw Y, Teller C, Colón-Ramos U. The burden of underweight and overweight among women in Addis Ababa, Ethiopia. BMC Public Health 2014;14(1126):1-11.

10. Neupane S, Prakash K, Doku DT. Overweight and obesity among women: analysis of demographic and health survey data from 32 sub-Saharan African countries. BMC Public Health. 2016;16(1):30.

11. Shayo GA, Mugusi FM. Prevalence of obesity and associated risk factors among adults in Kinondoni municipal district, Dar es salaam Tanzania. Shayo and Mugusi. BMC Public Health. 2011;11(365)

12. Msyamboza KP, Kathyola D, Dzowela T. Anthropometric measurements and prevalence of underweight, overweight and obesity in adult Malawians: nationwide population based NCD STEPS survey. Pan African Medical Journal. 2013;15(1)

13. Abrha S, Shiferaw S, Ahmed KY. Overweight and obesity and its sociodemographic correlates among urban Ethiopian women: evidence from the 2011 EDHS. BMC Public Health. 2016;16(1):636.

14. Bereket: Prevalence of Metabolic Syndrome among WorkingAdults in Ethiopia. Int J Hypertens 2011, 2011:2-8

15. Abrha S, Shiferaw S, Ahmed KY. Overweight and obesity and its sociodemographic correlates among urban Ethiopian women: evidence from the2011 EDHS. BMC Public Health. 2016;16(636):1-7.

16. Moges B, Amare B, Fantahun B, Kassu A. High prevalence of overweight, obesity, and hypertension with increased risk to cardiovascular disorders among adults in northwest Ethiopia: a cross sectional study. BMC Cardiovasc Disord. 2014;14(1):155

17. Pawar PPSA: Prevalence of overweight \& obesity in adult urban women. J Evol Med Dent Sci 2013, 2(4):364-367.

18. Gbary: Prevalence and risk factors of overweight and obesity: findings from a cross-sectional community-based survey in Benin. 2014:1-8.

19. Wachira Njuguna CM, Paul SK P, Sharma D, Dharmaraj DK. A cross sectional study on obesity among adult women (>18Years) in a semi urban area in Chennai. GJRA - GLOBAL JOURNAL FOR RESEARCH ANALYSIS. 2015;4(5):184-6

20. GUP I, AN A, BO N, VC U. Obesity in adult Nigerians: a study of its pattern and common primary co-morbidities in a rural mission general Hospital in Imo state, south-eastern Nigeria. Niger J Clin Pract. 2011;14(2):212-8.

21. Handan Wand GR: High prevalence of obesity among women who enrolled in HIV prevention trials in KwaZulu-Natal, South Africa: healthy diet and life style messages should be integrated into HIV prevention programs. BMC Public Health2013,13:159 2013, 13(159):1-5.

22. Tzotzas T, et al. Marital status and educational level associated to obesity in Greek adults: data from the National Epidemiological Survey. BMC Public Health. 2010;10(732):1-8

23. Addo PN, Nyarko KM, Sackey SO, Akweongo P, Sarfo B. Prevalence of obesity and overweight and associated factors among financial institution workers in Accra metropolis, Ghana: a cross sectional study. BMC Res Notes. 2015;8(599):1-8

24. Iwuala SO, et al. Obesity among health service providers in Nigeria: danger to long term health worker retention? Pan African Medical Journal. 2015; 22(1):1-8.

25. Alaba O, Chola L. Socioeconomic inequalities in adult obesity prevalence in South Africa: a decomposition analysis. Int J Environ Res Public Health. 2014 11:3387-406.

26. Priya SPS: A Descriptive Study To assess the knowledge on prevention and complications of obesity among adult population in out patient department at selected hospital Chennai. INDIAN JOURNAL OF APPLIED RESEARCH 2016, 6(2):577-578.

27. Amare B, Moges B, Moges F, Fantahun B, Admassu M, Mulu A, Kassu A. Nutritional status and dietary intake of urban residents in Gondar, Northwest Ethiopia. BMC Public Health. 2012;12(752)

28. Kuzmar I, Rizo MM, Cortes E. Social Classes, Level of Education, Marital Status, Alcohol and Tobacco Consumption as Predictors in a Successful Treatment of Obesity. J Nutr Disorders Ther. 2014:4(135).
29. Msyamboza KP, Kathyola D, Dzowela T. Anthropometric measurements and prevalence of underweight, overweight and obesity in adult Malawians: nationwide population based NCD STEPS survey. Pan African Medical Journal. 2013;15(108)

30. Amare B, Moges B, Moges F, Fantahun B, Admassu M, Mulu A, Kassu A. Nutritional status and dietary intake of urban residents in Gondar, Northwest Ethiopia. BMC Public Health. 2012;12(1):752.

31. WHO: The WHO STEPwise approach to chronic disease risk factor surveillance (STEPS) In.

32. Cogill B: Anthropometric Indicators Measurement Guide. In.: Food and Nutrition Technical Assisitance 2003.

33. Shayo GA, Mugusi FM. Prevalence of obesity and associated risk factors among adults in Kinondoni municipal district, Dar es salaam Tanzania. BMC Public Health. 2011;11(1):365

34. Kasu ES, Ayim A, Tampouri J: Prevalence of obesity among health workers in Kadjebi District of Ghana. 2015.

35. Shinde PP, Pawar A, Shinde PP. Prevalence of overweight \& obesity in adult urban women. J Evol Med Dent Sci. 2013;2(4):364-8.

36. El-Hazmi M, Warsy A. Relationship between age and the prevalence of obesity and overweight in Saudi population. Bahrain Medical Bulletin. 2002; 24(2):1-7.

37. Short KR, Vittone JL, Bigelow ML, Proctor DN, Nair KS. Age and aerobic exercise training effects on whole body and muscle protein metabolism. American Journal of Physiology-Endocrinology and Metabolism. 2004;286(1): E92-E101.

38. Short KR, Vittone UL, Bigelow ML, Proctor DN, Rizza RA, Coenen-Schimke JM, Nair KS. Impact of aerobic exercise training on age-related changes in insulin sensitivity and muscle oxidative capacity. Diabetes. 2003;52(8):1888-96.

\section{Submit your next manuscript to BioMed Central and we will help you at every step:}

- We accept pre-submission inquiries

- Our selector tool helps you to find the most relevant journal

- We provide round the clock customer support

- Convenient online submission

- Thorough peer review

- Inclusion in PubMed and all major indexing services

- Maximum visibility for your research

Submit your manuscript at www.biomedcentral.com/submit 